\title{
Transcriptome sequencing analysis reveals the effect of combinative treatment with low-intensity pulsed ultrasound and magnesium ions on hFOB1.19 human osteoblast cells
}

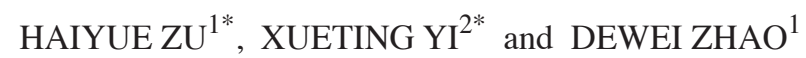 \\ ${ }^{1}$ Department of Orthopedics, Affiliated Zhongshan Hospital of Dalian University, Dalian, Liaoning 116001; \\ ${ }^{2}$ Department of Ultrasound, Affiliated Suzhou Hospital of Nanjing Medical University, Suzhou, Jiangsu 215008, P.R. China
}

Received October 27, 2017; Accepted March 29, 2018

DOI: $10.3892 / \mathrm{mmr} .2018 .9006$

\begin{abstract}
Biodegradable magnesium (Mg) materials are considered ideal as osteosynthesis implants. However, clinical application has proven complex. This is primarily associated with the issue of reducing the extent of implant degradation to a range acceptable for the human body, while simultaneously enhancing osteogenesis or osteoinduction. In the present study, a combination of $\mathrm{Mg}$ ions and low-intensity pulsed ultrasound (LIPUS) treatment was applied in hFOB 1.19 human osteoblast cells as a potential strategy to resolve this issue. A total of 7,314 differentially expressed genes (DEGs) and 826 shared DEGs in hFOB1.19 osteoblast cells were identified by microarray analysis following treatment with $\mathrm{Mg}$ and/or LIPUS. Gene Ontology analysis demonstrated that among cells treated with a combination of $\mathrm{Mg}$ and LIPUS, DEGs were significantly enriched in various functional annotations, including 'wound healing', 'transforming growth factor beta receptor signaling pathway', 'transcription, DNA-templated', 'receptor complex', 'nucleus', 'SMAD protein complex', 'DNA binding', 'metal ion binding' and 'GTPase activator activity'. Notably, the transforming growth factor (TGF)- $\beta$, mitogen-activated protein kinase (MAPK) and tumor necrosis factor (TNF) signaling pathways were preferentially overrepresented in the $\mathrm{Mg}$ and LIPUS combination group, which was subsequently confirmed by reverse transcription-quantitative polymerase chain reaction. Furthermore, genes involved in osteoblast mineralization promotion, including bone morphogenetic protein 6 , noggin, bone morphogenetic protein receptor (BMPR)1A, BMPR2 and SMAD 5/8, were significantly
\end{abstract}

Correspondence to: Professor Dewei Zhao, Department of Orthopedics, Affiliated Zhongshan Hospital of Dalian University, 6 Jiefang Street, Dalian, Liaoning 116001, P.R. China

E-mail: zhaodewei2016@163.com

${ }^{*}$ Contributed equally

Key words: biodegradable magnesium implant, low-intensity pulsed ultrasound, gene expression, osteoinduction, biosafety upregulated following combination treatment compared with the control group. Genes involved in the promotion of migration, including c-Jun N-terminal kinase, doublecortin, paxillin and Jun proto-oncogene AP-1 transcription factor subunit, were also upregulated in the combination treatment group compared with the control group. The DEG data were supported by morphological observations of the osteoblasts using alizarin red $\mathrm{S}$ staining and wound healing assays, which indicated that Mg and LIPUS combinative treatment had a synergistic effect on osteoblast mineralization and migration. Additionally, the combined treatment significantly upregulated metal transporter genes associated with Mg entry, including ATPase $\mathrm{Na}^{+} / \mathrm{K}^{+}$-transporting subunit $\alpha 1$, cyclin and CBS domain divalent metal cation transport mediator 2, $\mathrm{K}^{+}$voltage-gated channel subfamily $\mathrm{J}$ member 14 , transient receptor potential cation channel (TRP) subfamily $\mathrm{M}$ member 7 and TRP subfamily V member 2 . In summary, the findings of the present study revealed that combined stimulation with $\mathrm{Mg}$ and LIPUS may exhibit a synergistic effect on human osteoblast bone formation through the TGF- $\beta$, MAPK and TNF signaling pathways, while also facilitating Mg influx. The present study demonstrated the potential of combinative LIPUS and Mg treatment as a novel therapeutic strategy for enhancing the osteoinduction, biocompatibility and biosafety of biodegradable $\mathrm{Mg}$ implants.

\section{Introduction}

Magnesium (Mg) and its alloys have been applied as implants in the field of orthopedics for over 100 years (1). Magnesium materials are currently regarded as ideal osteosynthesis implants due to their favorable properties, including low elastic modulus, biodegradability and osteoconductivity (2). In our previous study, specifically designed high purity $\mathrm{Mg}$ screws were administered during surgery to repair vascularized bone flaps in patients with stage II/III osteonecrosis (3). $\mathrm{Mg}$ ions are the second largest intracellular cations and the fourth most abundant cations in the human body (4). They are considered to have critical roles in various biological processes, including enzyme function, ion channel regulation, metabolism maintenance and genomic stability (5). Of the total $\mathrm{Mg}$ within the body, 50 60\% of $\mathrm{Mg}$ resides as 
surface substituents of the hydroxyapatite mineral component of bone. Therefore, these ions are essential in skeletal metabolism and development (6). At present, the mechanism of $\mathrm{Mg}$ ions in stimulating bone regenerationis thought to occur through several classical signaling events, including the phosphoinositide 3-kinase (PI3K)/Akt, transient receptor potential cation channel (TRP) subfamily M and SMAD pathways, as well as the osteoprotegerin/tumor necrosis factor (TNF) superfamily member 11 ratio (7-10). Mg ions may regulate the proliferation, migration and differentiation of both osteoblasts and osteoclasts during osteogenesis through these pathways.

However, the clinical use of Mg-based materials is restricted due to their rapid degradation rate, which leads to enhanced gas evolution, $\mathrm{pH}$ increase and $\mathrm{Mg}$ ion overdose upon degradation $(11,12)$. Saris et al (13) reported that a $\mathrm{Mg}$ plasma concentration of $3.5 \mathrm{mM}$ was the threshold level for human tolerance without concerns regarding health risks. Therefore, control of local $\mathrm{Mg}$ release while promoting efficient transport of $\mathrm{Mg}$ ions into bone tissue is critical for biosafety in the application of biodegradable orthopedic $\mathrm{Mg}$ implants. Although various modification strategies are able to reduce the corrosion of $\mathrm{Mg}$, including alloying (14) and certain surface treatments (15-17), the development of a strategy to reduce the degradation rate of $\mathrm{Mg}$ to an acceptable range for the human body, while simultaneously enhancing osteogenesis or osteoinduction, is required.

Low-intensity pulsed ultrasound (LIPUS) is a biophysical stimulation method that uses frequencies between $45 \mathrm{kHz}$ and $3 \mathrm{MHz}$, and acoustic intensities between 5 and $1,000 \mathrm{~mW} / \mathrm{cm}^{2}$ (18). It has been demonstrated to be a clinically safe and effective approach to accelerate or induce bone healing. In 1994, FDA approval was first granted to Exogen for a fracture healing LIPUS device, which uses a $1.5 \mathrm{MHz}$ ultrasound wave pulsed at $1 \mathrm{kHz}$, with a $20 \%$ duty cycle at a spatial average temporal average intensity of $30 \mathrm{~mW} / \mathrm{cm}^{2}$, applied for $20 \mathrm{~min}$ per day $(18,19)$. This ultrasound-accelerated fracture healing system has been used in the vast majority of published research and clinical studies. LIPUS may accelerate bone formation in vitro by regulating a series of factors, including $\mathrm{Ca}^{2+}$, nitric oxide, prostaglandins and bone morphogenetic proteins (BMPs) (20-24). In vivo, LIPUS has demonstrated great potential to assist freshfracture healing and shorten both cortical and endosteal union times. Notably, LIPUS exerts a potent effect on non-operatively managed fractures (25-28). Due to its efficacy, safety and conservative application, as supported by data from independent organizations, LIPUS is commonly used in clinical practice (19).

As the effects of LIPUS are evident, it is currently regarded as an auxiliary tool to accelerate bone formation in the field of biomaterial science. Zhou et al (29) observed improved osteogenesis of human bone marrow mesenchymal stem cells (MSCs) following LIPUS treatment in a 3D bio-printed scaffold containing Arg-Gly-Asp-Serpeptide and nano-hydroxyapatite. Additionally, Nagasaki et al (30) demonstrated that LIPUS enhances the osteogenesis of adipose-derived stem cells on a nano-hydroxyapatite biomaterial scaffold. Therefore, the integration of LIPUS and bioactive scaffolds may overcome the limitations of bone grafting and other available surgical reconstructive techniques, by delivering osteoprogenitor cells to bone defects, which may provide novel clinical applications for bone regeneration. It has also been reported that ultrasound as a mechanical stimulus mediates cellular discharge by activating mechanosensitive ion channels embedded within cellular membranes (31). These findings provide a basis for investigation into the effects of ultrasound on ion channels expressed in neurons, retinal cells and osteoblast cells, which may have important medical applications.

Considering the promising therapeutic method of LIPUS, we hypothesized that a combinative treatment of LIPUS and $\mathrm{Mg}$ ions may be capable of effectively producing a synergistic effect on human osteoblasts, to ultimately promote osteogenesis in bone tissue. Furthermore, it was assumed that this application may overcome the inherent limitation of $\mathrm{Mg}$ materials in clinical use. The aim of the present study was to evaluate the combined efficacy of administering Mg ions and LIPUS to human osteoblasts and to investigate the underlying molecular mechanisms and signaling pathways that may be involved in the enhanced osteoinduction, biocompatibility and biosafety of biodegradable $\mathrm{Mg}$ implants in combination with LIPUS.

\section{Materials and methods}

Cell culture. Human fetal osteoblasts (hFOB1.19; American Type Culture Collection, Manassas, VA, USA) were cultured in Dulbecco's modified Eagle's medium/Ham's F12 medium (DMEM/F12; Hyclone; GE Healthcare Life Sciences, Logan, UT, USA) supplemented with $10 \%$ fetal bovine serum (Hyclone; GE Healthcare Life Sciences), 0.1\% L-glutamine and $1 \%$ penicillin/streptomycin. Cultures were maintained at $37^{\circ} \mathrm{C}$ in a humidified atmosphere with $5 \% \mathrm{CO}_{2}$ and were harvested once a week using trypsin-EDTA solution (Hyclone; GE Healthcare Life Sciences). The cells were subsequently dividedinto four groups: Control ( $0.8 \mathrm{mM} \mathrm{Mg}$, no LIPUS), LIPUS only ( $0.8 \mathrm{mM} \mathrm{Mg}+$ LIPUS), $\mathrm{Mg}$ only ( $3 \mathrm{mM} \mathrm{Mg}$, no LIPUS) and combination ( $3 \mathrm{mM} \mathrm{Mg}+$ LIPUS).

Ultrasound treatment. hFOB1.19 cells at the fifth or sixth passage were subjected to LIPUS. The LIPUS device consisted of a sonic accelerated fracture-healing system device (Exogen; Bioventus, LLC, Durham, NC, USA), which was used to generate a $1.5 \mathrm{MHz}$ and $30 \mathrm{~mW} / \mathrm{cm}^{2}$ pulsed-wave at a duty ratio of $20 \%$. LIPUS was administered for $20 \mathrm{~min}$ every day for durations described below in the following experiments. The culture plates were placed on the ultrasound transducer array conducted by a thin layer of coupling gel. All LIPUS treatments were performed on the culture plates in the tissue culture in a $5 \% \mathrm{CO}_{2}$ incubator at $37^{\circ} \mathrm{C}$. Furthermore, LIPUS was applied simultaneously with $\mathrm{Mg}$ treatment in the combination group.

Preparation of culture medium with $\mathrm{Mg}$ sulfate. A sterilized solution of concentrated $\mathrm{Mg}$ sulfate $(0.5 \mathrm{M})$ was used to increase the $\mathrm{Mg}$ ion concentration to reach an accumulation of $0.8,2,3,5,10,15$ and $20 \mathrm{mM}$ in the basal culture medium.

Cell proliferation assay. A colorimetric Cell Counting Kit-8 (CCK-8) assay (Dojindo Molecular Technologies, Inc., Kumamoto, Japan) was used to assess cell proliferation. hFOB1.19 cells were seeded at a density of 4,000 cells/well in 
96-well plates. The medium was exposed to treatment with $\mathrm{Mg}$ alone, LIPUS alone or combined stimulation with both treatments. After culturing at $37^{\circ} \mathrm{C}$ for $1,3,5$ or 7 days, cells were treated with $10 \mu \mathrm{l}$ CCK-8 reagent per well and then incubated at $37^{\circ} \mathrm{C}$ for $2 \mathrm{~h}$. Subsequently, the optical density was determined with a spectrometer at a wavelength of $450 \mathrm{~nm}$. Each experiment was performed in triplicate.

Alizarin red $S$ staining. To detect extracellular matrix calcium deposits as a measure of bone nodule formation, the cellular matrix was stained with Alizarin red $\mathrm{S}$ dye, which combines with $\mathrm{Ca}^{2+}$ in the matrix. hFOB1.19 cells were seeded in 6 -well plates at a density of $5 \times 10^{4}$ cells per well. Cells were treated with osteogenic medium containing DMEM/F12 with the addition of $10 \mathrm{mM} \beta$-glycerol phosphate (Sigma-Aldrich; Merck KGaA, Darmstadt, Germany) and $50 \mu \mathrm{g} / \mathrm{ml}$ ascorbic acid (Sigma-Aldrich; Merck KGaA) to induce osteoblast differentiation. Control, $\mathrm{Mg}$ only, LIPUS only and combination treatments were performed while cells were incubated in the osteogenic medium at $37^{\circ} \mathrm{C}$ and $5 \% \mathrm{CO}_{2}$ for 14 days. After that, cells were washed twice with PBS and fixed with $4 \%$ formaldehyde for $10 \mathrm{~min}$ at room temperature. The cells were stained with $40 \mathrm{mM}$ alizarin red S solution (Sigma-Aldrich; Merck KGaA) at $\mathrm{pH} 4.4$ for $40 \mathrm{~min}$ at room temperature and rinsed twice with deionized water. Images of the stained cells were captured at X100 magnification using the digital camera of a phase contrast light microscope. A total of 6 different fields from each sample were analyzed using Image-Pro Plus 6.0 software (Media Cybernetics, Inc., Rockville, MD, USA).

Wound healing assay. hFOB1.19 cells were seeded onto 6-well plates at a density of $2 \times 10^{5}$ cells per well. Cell monolayers were wounded by scratching the surface as uniformly as possible with a pipette tip, following which control, Mg only, LIPUS only and combination treatments were performed at $37^{\circ} \mathrm{C}$ and $5 \%$ $\mathrm{CO}_{2}$ for $24 \mathrm{~h}$. Images of this initial wounding and the movement of cells into the scratched area were captured at X100 magnification using an inverted light microscope linked to a CoolSNAP ES charged-coupled device camera (Photometrics, Tucson, AZ, USA). Six different fields from each sample were analyzed using Image-Pro Plus 6.0 software for quantitative estimations of the number of cells that had migrated into the wounded area.

Microarray analysis. Microarray analysis was performed by Shanghai Oebiotech Co., Ltd. (Shanghai, China) using the SurePrint G3 Human Gene Expression 8x60 K v3 microarray (Agilent Technologies, Inc., Santa Clara, CA, USA) to analyze samples of the four groups. Control, $\mathrm{Mg}$ only, LIPUS only and combination treatments were performed at $37^{\circ} \mathrm{C}$ and $5 \% \mathrm{CO}_{2}$ for 7 days. Subsequently, total RNA was extracted by TRIzol reagent (Thermo Fisher Scientific, Inc., Waltham, MA, USA) and quantified with a NanoDrop 2000 spectrophotometer (NanoDrop Technologies; Thermo Fisher Scientific, Inc.) and RNA integrity was assessed using an Agilent Bioanalyzer 2100 (Agilent Technologies, Inc.). The sample labeling (Low Input Quick-Amp Labeling kit, one-color Agilent Technologies, Inc.), microarray hybridization (Gene Expression Hybridization kit, Agilent Technologies, Inc.) and washing (Gene Expression Wash Pack, Agilent Technologies,
Inc.) were performed according to the manufacturer's protocols. Briefly, total RNA was reverse transcribed to double stranded cDNA, then synthesized into cRNA and labeled with cyanine-3-cytidine triphosphate according to the manufacturer's protocols of Low Input Quick-Amp Labeling kit. The labeled cRNAs were hybridized onto the microarray. The arrays were subsequently scanned with an Agilent G2505C scanner (Agilent Technologies, Inc.) and the acquired array images were analyzed using Agilent Feature Extraction software (version 10.7.1.1, Agilent Technologies, Inc.) with performance of background subtractions.

Gene ontology(GO), Kyoto Encyclopedia of Genes and Genomes (KEGG) and heat map pathway analysis. To make pairwise comparisons of global alterations in gene expression between groups, a Venn diagram (version 2.0; http://bioinformatics.psb. ugent.be/webtools/Venn/) was constructed. Then differentially expressed genes (DEGs; fold change $\geq 2$ and $\mathrm{P}<0.05$ ) were selected for GO (http://www.geneontology.org) and KEGG pathway (http://www.genome.jp/kegg) analyses, following basic analysis of the raw data with GeneSpring (version 13.1; Agilent Technologies, Inc.). GO analysis describes gene attributes in three categories: 'Biological process', 'cellular component' and 'molecular function'. Based on the GO categories, all DEGs were classified under different $\mathrm{GO}$ terms according to their characteristics and the enrichment of the GO terms was calculated. The KEGG database was used to further characterize the metabolic pathways of the DEGs and the enrichment of the different pathways was also calculated. Heat map software Seaborn, version 0.8.1 (http://seaborn.pydata.org/) was employed to show graphical representation of data from top 3 KEGG upregulated pathways where individual values contained in a matrix were represented as colors.

Reverse transcription-quantitative polymerase chain reaction (RT-qPCR) validation. To validate the microarray data, six differentially expressed mRNAs associated with osteogenesis were selected. Control, $\mathrm{Mg}$ only, LIPUS only and combination treatments were performed at $37^{\circ} \mathrm{C}$ and $5 \% \mathrm{CO}_{2}$ for 7 days. After that, total RNA from $\sim 10^{6}$ cells was isolated using the RNeasy Mini kit (Qiagen, Valencia, CA, USA) according to the manufacturer's protocols. cDNA synthesis conducted via RT fromtotal RNA using the PrimeScript ${ }^{\mathrm{TM}}$ II 1st strand cDNA Synthesis kit (Takara Bio, Inc., Otsu, Japan), which consisted of $4.0 \mu \mathrm{l}$ Prime Scriptbuffer, $1.0 \mu \mathrm{l}$ oligo dT primers, $1.0 \mu \mathrm{l}$ random 6-mers and $1.0 \mu 1$ PrimeScript RT Enzyme Mix I. Reactions were performed in a RT-PCR reaction system (Eppendorf, Hamburg, Germany) for $15 \mathrm{~min}$ at $37^{\circ} \mathrm{C}$, which was followed by heat inactivation of the RT reaction for $5 \mathrm{sec}$ at $85^{\circ} \mathrm{C}$. The RT reaction mixture was subsequently diluted $\mathrm{x} 10$ in RNase-free water and held at $-20^{\circ} \mathrm{C}$.

qPCR was performed using a QuantStudio 7 Flex Real-Time PCR System (Thermo Fisher Scientific, Inc.) with $20 \mu \mathrm{l}$ PCR reaction mixture that included $1 \mu \mathrm{l} \mathrm{cDNA}$, $1 \mu$ l Power SYBRGreen PCR Master Mix (Thermo Fisher Scientific, Inc.), $1 \mu \mathrm{l}$ forward primer, $1 \mu 1$ reverse primer and $17 \mu 1$ RNase-free water. Reaction mixtures were incubated in a MicroAmp 96-well reaction plate (Thermo Fisher Scientific, Inc.) at $95^{\circ} \mathrm{C}$ for $10 \mathrm{~min}$, which was followed by 40 cycles at $95^{\circ} \mathrm{C}$ for $15 \mathrm{sec}$ and $60^{\circ} \mathrm{C}$ for $1 \mathrm{~min}$. Melting curve analysis was 
Table I. Primer sequences used in reverse transcription-quantitative polymerase chain reaction analysis.

\begin{tabular}{|c|c|c|}
\hline Gene & Direction & Sequence \\
\hline \multirow[t]{2}{*}{ BMPR2 } & $\mathrm{F}$ & 5'-CATGGCATGGGTGGAATTAGAG-3' \\
\hline & $\mathrm{R}$ & 5'-GCAGCCTGTGAACACGTAGTGA-3' \\
\hline \multirow[t]{2}{*}{ TGF- $\beta$} & $\mathrm{F}$ & 5'-TTACACTGTCCCTGCTGCACTT-3' \\
\hline & $\mathrm{R}$ & 5'-GGTATATGTGGAGGTGCCATCAA-3' \\
\hline \multirow[t]{2}{*}{ JNK } & $\mathrm{F}$ & 5'-TGAGAAACTCTTCCCTGATGTCCTT-3 \\
\hline & $\mathrm{R}$ & 5'-GATAACAAATCCCTTGCCTGACTG-3' \\
\hline \multirow[t]{2}{*}{ p38 } & $\mathrm{F}$ & 5'-TGTGATGTGGTGCGTGTGA-3' \\
\hline & $\mathrm{R}$ & 5'-AGGAACCGAGGAGAGGGAAG-3' \\
\hline \multirow[t]{2}{*}{ TNF- $\alpha$} & $\mathrm{F}$ & 5'-CTGCCTGCTGCACTTTGGAG-3' \\
\hline & $\mathrm{R}$ & 5'-ACATGGGCTACAGGCTTGTCACT-3' \\
\hline \multirow[t]{2}{*}{ TRPM7 } & $\mathrm{F}$ & 5'-ACAGAGGGAAGGGACCCTCAA-3' \\
\hline & $\mathrm{R}$ & 5'-ACCAGGCAGCAAGCAAGGTATT-3' \\
\hline \multirow[t]{2}{*}{ GAPDH } & $\mathrm{F}$ & 5'-GCACCGTCAAGGCTGAGAAC-3' \\
\hline & $\mathrm{R}$ & 5'-TGGTGAAGACGCCAGTGGA-3' \\
\hline
\end{tabular}

F, forward; R, reverse; BMPR2, bone morphogenetic protein receptor 2 ; TGF- $\beta$, transforming growth factor- $\beta$; JNK, c-Jun N-terminal kinase; TNF, tumor necrosis factor; TRPM7, transient receptor potential cation channel subfamily M member 7.

subsequently performed to validate the specific generation of the expected PCR product. Three independent experiments were performed with each sample run in triplicate. The primers are listed in Table I and were synthesized by Takara Bio, Inc. The expression levels of mRNAs were normalized to GAPDH and were calculated using the $2^{-\Delta \Delta C q}$ method (32).

Statistical analysis. Each experiment was performed at least three times. Data are presented as the mean \pm standard deviation. One-way and two-way analysis of variance with Fisher's least significant difference post-hoc test were performed using SPSS Data Editor Version 22.0 (IBM Corp., Armonk, $\mathrm{NY}$, USA). $\mathrm{P}<0.05$ was considered to indicate a statistically significant difference.

\section{Results}

Effect of $\mathrm{Mg}$ and LIPUS combinative treatment on cell proliferation. The CCK- 8 assay results revealed that $\mathrm{Mg}$ ions influenced the proliferation of hFOB1.19 cells in a concentration-dependent manner. As presented in Fig. 1A, the proliferation of the cells was tested at $\mathrm{Mg}$ concentrations of $0.8,2,3,5,10,15$ and $20 \mathrm{mM}$ for $24 \mathrm{~h}$. At the relatively low concentrations of $\mathrm{Mg}$ ions, the proliferation of the osteoblasts gradually increased with concentration. The peak critical effective dose was determined to be $5 \mathrm{mM}$, which exerted a significant effect on proliferation compared with the control concentration $(0.8 \mathrm{mM} ; \mathrm{P}<0.05)$. However, no stimulatory effect of the $\mathrm{Mg}$ ions on osteoblast proliferation was observed when the concentration of $\mathrm{Mg}$ exceeded $15 \mathrm{mM}$.

The combinative treatment of $\mathrm{Mg}$ ions and LIPUS for $24 \mathrm{~h}$ resulted in a synergistic effect on cell proliferation at low $\mathrm{Mg}$ concentrations. The control group was treated with $0.8 \mathrm{mM}$ $\mathrm{Mg}$ only. As above, cell proliferation was not promoted when the concentration of $\mathrm{Mg}$ exceeded $15 \mathrm{mM}$ (Fig. 1B). However, with exposure to LIPUS in combination with Mg ions, the peak critical effective dose occurred at a lower $\mathrm{Mg}$ concentration of $3 \mathrm{mM}$ (Fig. 1B), compared with $5 \mathrm{mM}$ with $\mathrm{Mg}$ treatment alone in Fig. 1A, which was further investigated in the subsequent experiments. The concentration of $3 \mathrm{mM}$ was the optimum $\mathrm{Mg}$ dose to stimulate the combined effect of $\mathrm{Mg}$ and LIPUS. Therefore, the following experiments were performed using a $\mathrm{Mg}$ concentration of $3 \mathrm{mM}$ to investigate the combinative effect of Mg and LIPUS treatment.

Additionally, further detailed validation via a CCK-8 assay was performed after 1, 3,5 and 7 days of treatment. As presented in Fig. 1C, the proliferation of hFOB 1.19 cells was significantly increased in the $\mathrm{Mg}$ alone group after 3 days, compared with the control. The proliferation of hFOB 1.19 cells gradually increased in the LIPUS alone group past day 3 of culture. Furthermore, to confirm whether the effect of combinative treatment was synergistic, the assay was performed following the combinative treatment. The results revealed that the combinative treatment of $\mathrm{Mg}$ and LIPUS significantly increased proliferation compared with each individual treatment, even at day $1(\mathrm{P}<0.01$; Fig. 1C). This indicated that synergy took effect at the earliest time point and had a sustained effect on enhancing osteoblast proliferation.

Global alterations in gene expression. To further examine the mechanism and interaction of signaling pathways underlying the synergic effect of $\mathrm{Mg}$ and LIPUS, microarray analysis was performed, in which data fluctuations above 2-fold were considered to represent significant differential expression. As presented in Fig. 2, a Venn diagram was constructed for pairwise comparisons of the four groups, which depicted the 7,314 DEGs identified in total and the 826 shared DEGs in hFOB1.19 cells cultured following $\mathrm{Mg}$ and/or LIPUS treatment. Compared with the control group, data from the LIPUS only and $\mathrm{Mg}$ only groups indicated 1,687 and 3,967 DEGs, respectively. Notably, Mg and 

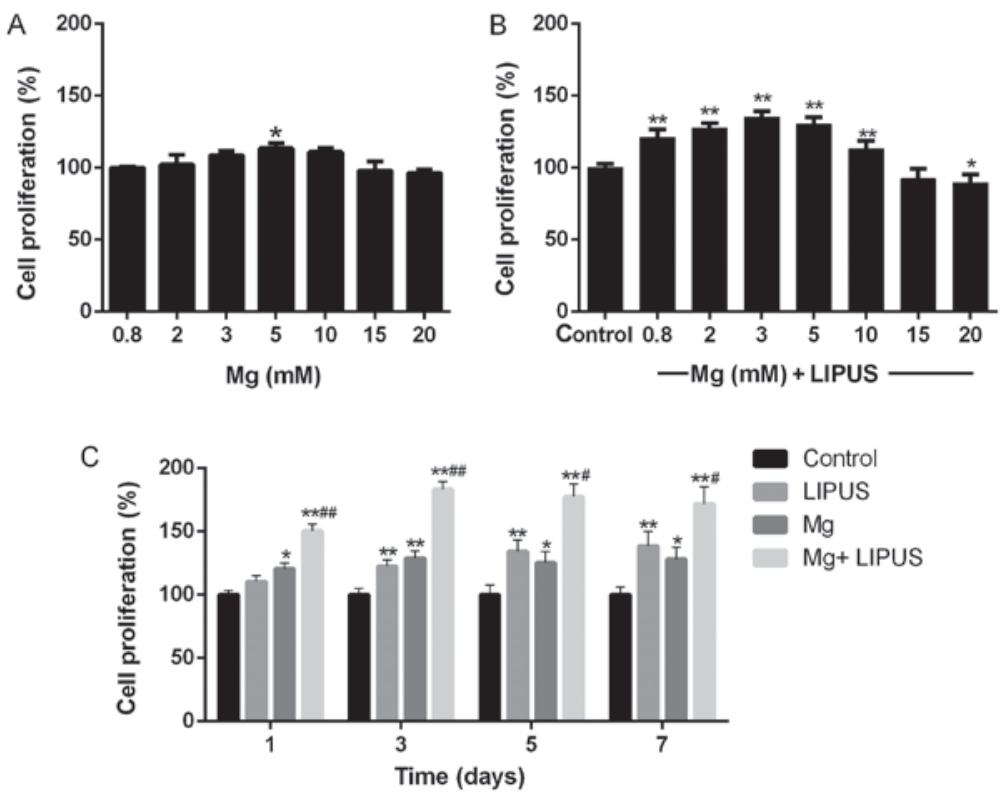

Figure 1. Cell proliferation was determined with a Cell Counting Kit-8 assay. (A) Osteoblast proliferation was affected by Mg in a concentration-dependent manner. "P $<0.05$ vs. $0.8 \mathrm{mM}$ group. (B) Combinative treatment of Mg and LIPUS for $24 \mathrm{~h}$ had a synergistic effect on cell proliferation, within a relatively low $\mathrm{Mg}$ concentration range. The control group in (B) were treated with $0.8 \mathrm{mM} \mathrm{Mg}$ only. ${ }^{*} \mathrm{P}<0.05$ and ${ }^{* * *} \mathrm{P}<0.01 \mathrm{vs}$. control group. (C) Effects of LIPUS alone, Mg alone and combination treatment on osteoblast proliferation after $1,3,5$ and 7 days of treatment. ${ }^{*} \mathrm{P}<0.05$ and ${ }^{* * *} \mathrm{P}<0.01$ vs. control group; ${ }^{\#} \mathrm{P}<0.05$ and ${ }^{\# \#} \mathrm{P}<0.01$ vs. Mg alone and LIPUS alone groups. $\mathrm{n}=3$. Mg, magnesium; LIPUS, low-intensity pulsed ultrasound.

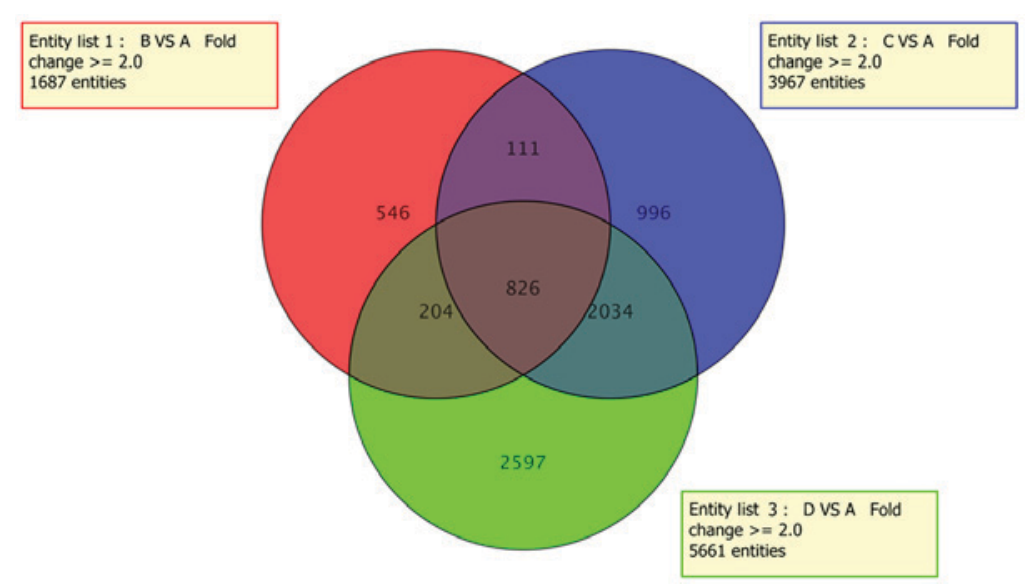

Figure 2. Venn diagram of the identified DEGs. A indicates the control group, B indicates the LIPUS alone group, C indicates the Mg alone group and D indicates the combined Mg + LIPUS treatment group. The number of DEGs in the four groups is presented. The numbers indicate the genes expressed in each segment. An absolute value of fold enrichment $\geq 2$ was set as the threshold to determine significance. DEGs, differentially expressed genes; LIPUS, low-intensity pulsed ultrasound; Mg, magnesium.

LIPUS combinative treatment resulted in a total of 5,661 DEGs, including 2,701 upregulated and 2,960 downregulated genes.

GO classification of DEGs in the Mg and LIPUS combination group. GO analysis of the microarray data was performed to obtain an overview of the cellular physiological events represented by the upregulated DEGs in cells of the combined treatment group. The thresholds of the GO terms were set as $\mathrm{P}<0.05$ and an absolute value of fold enrichment $\geq 2$. Enrichment analysis was performed with respect to the three GO categories: 'Biological process', 'molecular function' and 'cellular component'. As presented in Table II, 'wound healing' (GO: 0042060), 'transforming growth factor beta receptor signaling pathway' (GO: 0007179) and 'transcription,
DNA-templated' (GO: 0006351) were the most significantly enriched 'biological process' terms. 'Receptor complex' (GO: 0043235), 'nucleus' (GO: 0005634) and 'SMAD protein complex' (GO: 0071141) were the most enriched 'cellular component terms' (Table II). Furthermore, 'DNA binding' (GO: 0003677), 'metal ion binding' (GO: 0046872) and 'GTPase activator activity' (GO: 0005096) were the most enriched molecular function terms (Table II).

Determination of signaling pathways that are influenced by $\mathrm{Mg}$ and LIPUS combinative treatment. KEGG analysis was used to determine the signaling pathway enrichment of DEGs induced by combinative treatment. The significance threshold was a $\mathrm{P}<0.05$. As presented in Table III, the 
Table II. GO classification of the identified differentially expressed genes in the combined magnesium and low-intensity pulsed ultrasound treatment group.

A, Enriched biological process terms

\begin{tabular}{|c|c|c|c|}
\hline GO items & GO terms & Genes & P-value \\
\hline GO:0042060 & Wound healing & 20 & $1.59 \times 10^{-5}$ \\
\hline GO:0007179 & Transforming growth factor beta receptor signaling pathway & 28 & $1.89 \times 10^{-5}$ \\
\hline GO:0006351 & Transcription, DNA-templated & 191 & $9.78 \times 10^{-5}$ \\
\hline GO:0060394 & Negative regulation of pathway-restricted SMAD protein phosphorylation & 7 & $1.93 \times 10^{-4}$ \\
\hline GO:0045944 & Positive regulation of transcription from RNA polymerase II promoter & 105 & $5.42 \times 10^{-4}$ \\
\hline GO:0051056 & Regulation of small GTPase mediated signal transduction & 24 & $6.54 \times 10^{-4}$ \\
\hline GO:0035556 & Intracellular signal transduction & 50 & $9.36 \times 10^{-4}$ \\
\hline GO:0043547 & Positive regulation of GTPase activity & 58 & $1.27 \times 10^{-3}$ \\
\hline GO:0000165 & MAPK cascade & 17 & $1.37 \times 10^{-3}$ \\
\hline GO:0030336 & Negative regulation of cell migration & 17 & $1.37 \times 10^{-3}$ \\
\hline
\end{tabular}

B, Enriched cellular component terms

\begin{tabular}{|c|c|c|c|}
\hline GO items & GO terms & Genes & P-value \\
\hline GO:0043235 & Receptor complex & 23 & $5.11 \times 10^{-3}$ \\
\hline GO:0005634 & Nucleus & 444 & $3.71 \times 10^{-3}$ \\
\hline GO:0071141 & SMAD protein complex & 4 & $6.34 \times 10^{-3}$ \\
\hline GO:0005737 & Cytoplasm & 424 & $1.04 \times 10^{-2}$ \\
\hline GO:0015629 & Actin cytoskeleton & 27 & $1.57 \times 10^{-2}$ \\
\hline GO:0016604 & Nuclear body & 7 & $1.94 \times 10^{-2}$ \\
\hline GO:0005813 & Centrosome & 45 & $2.39 \times 10^{-2}$ \\
\hline GO:0005604 & Basement membrane & 12 & $2.53 \times 10^{-2}$ \\
\hline GO:0002116 & Semaphorin receptor complex & 3 & $3.22 \times 10^{-2}$ \\
\hline GO:0001518 & Voltage-gated sodium channel complex & 4 & $3.89 \times 10^{-2}$ \\
\hline
\end{tabular}

C, Enriched molecular function terms

\begin{tabular}{|c|c|c|c|}
\hline GO items & GO terms & Genes & P-value \\
\hline GO:0003677 & DNA binding & 175 & $2.42 \times 10^{-6}$ \\
\hline GO:0046872 & Metal ion binding & 208 & $3.93 \times 10^{-6}$ \\
\hline GO:0005096 & GTPase activator activity & 39 & $3.32 \times 10^{-4}$ \\
\hline GO:0008270 & Zinc ion binding & 129 & $1.11 \times 10^{-3}$ \\
\hline GO:0005515 & Protein binding & 746 & $2.15 \times 10^{-3}$ \\
\hline GO:0003700 & Transcription factor activity, sequence-specific DNA binding & 92 & $3.96 \times 10^{-3}$ \\
\hline GO:0070412 & R-SMAD binding & 7 & $3.98 \times 10^{-3}$ \\
\hline GO:0070411 & I-SMAD binding & 5 & $5.25 \times 10^{-3}$ \\
\hline GO:0046332 & SMAD binding & 10 & $5.68 \times 10^{-3}$ \\
\hline GO:0019902 & Phosphatase binding & 10 & $6.53 \times 10^{-3}$ \\
\hline
\end{tabular}

GO, gene ontology.

significantly enriched upregulated pathways included 'MAPK signaling pathway' (path: hsa04010), 'TNF signaling pathway' (path: hsa04668) and 'TGF-beta signaling pathway' (path: hsa04350). Additionally, the significantly enriched downregulated pathways included 'systemic lupus erythematosus' (path: hsa05322), 'alcoholism' (path: hsa05034) and 'viral carcinogenesis' (path: hsa05203), which had no clear connection with the focus of the present study.

The co-expression pattern of DEGs in hFOB1.19 osteoblasts may be a valuable tool for identifying important pathways 
Table III. Prediction of signaling pathways associated with magnesium and low-intensity pulsed ultrasound combinative treatment.

A, Upregulated pathways

\begin{tabular}{llll}
\hline KEGG ID & \multicolumn{1}{c}{ KEGG terms } & Genes & P-value \\
\hline path:hsa04010 & MAPK signaling pathway & 38 & $4.33 \times 10^{-5}$ \\
path:hsa04668 & TNF signaling pathway & 22 & $4.54 \times 10^{-5}$ \\
path:hsa04350 & TGF-beta signaling pathway & 17 & $1.76 \times 10^{-4}$ \\
path:hsa04621 & NOD-like receptor signaling pathway & 14 & $1.81 \times 10^{-4}$ \\
path:hsa04722 & Neurotrophin signaling pathway & 21 & $3.44 \times 10^{-4}$ \\
\hline
\end{tabular}

B, Downregulated pathways

\begin{tabular}{llrr}
\hline KEGG ID & \multicolumn{1}{c}{ KEGG terms } & Genes & P-value \\
\hline path:hsa05322 & Systemic lupus erythematosus & 35 & $2.10 \times 10^{-9}$ \\
path:hsa05034 & Alcoholism & 34 & $2.56 \times 10^{-6}$ \\
path:hsa05203 & Viral carcinogenesis & 28 & $2.58 \times 10^{-3}$ \\
path:hsa04010 & MAPK signaling pathway & 32 & $4.28 \times 10^{-3}$ \\
path:hsa04066 & HIF-1 signaling pathway & 16 & $6.94 \times 10^{-3}$
\end{tabular}

KEGG, Kyoto Encyclopedia of Genes and Genomes.

associated with osteogenesis. To elucidate these pathways in greater detail, co-expressed genes that may be associated with signaling pathways in osteogenesis were specifically searched for. KEGG enrichment analysis was conducted and 73 pathways that were significantly enriched among the DEGs were identified. Among the co-upregulated DEGs, KEGG analysis identified the top three signaling pathways to be the mitogen-activated protein kinase (MAPK; $\mathrm{P}=4.33 \times 10^{-5}$ ), tumor necrosis factor (TNF; $\mathrm{P}=4.54 \times 10^{-5}$ ) and transforming growth factor- $\beta$ (TGF- $\beta ; P=1.76 \times 10^{-4}$ ) signaling pathways, which were the most significantly enriched pathways in the combinative treatment group compared with the other treatment groups (Fig. 3). Closer examination of the pathway heat maps confirmed the enrichment of these three signaling pathways, as the majority of the DEGs associated with the pathways were upregulated following combined treatment (Fig. 4).

Expression profiles of representative DEGs associated with mineralization in the Mg and LIPUS combination group. The expression of bone morphogenetic protein BMP6, noggin (NOG), BMP receptor (BMPR)1A, BMPR2, SMAD5, SMAD8and TGF- $\beta$ was detected by microarray analysis as these genes are associated with bone mineralization. Compared with the control group, the expression of BMP6, NOG, BMPR2 and SMAD8 was decreased, in the LIPUS only treatment group. In the Mg only group, NOG, BMPR1A and BMPR2 were increased, while SMAD5 expression was decreased, compared with the control group. Notably, in the combination treatment group, the expression of BMP6, NOG, BMPR1A, BMPR2, SMAD5 and TGF- $\beta$ was significantly increased compared with control, while the expression of NOG, BMPR2 and TGF- $\beta$ was significantly increased compared with Mg only and LIPUS only groups, indicating that the combination of $\mathrm{Mg}$ and LIPUS had a synergistic effect on mineralization (Fig. 5).

These data were also consistent with the alizarin red $\mathrm{S}$ staining results, which measured the stimulatory effect of isolative or combinative treatment on the ability of hFOB 1.19 to differentiate into mature osteoblasts and form a mineralized extracellular matrix. Images of alizarin red $\mathrm{S}$ staining were captured at 0 and 14 days of culture (Fig. 6A). The results revealed that after day 14 of culture, the osteoblasts exhibited progressive stages of matrix mineralization. Stimulation with LIPUS alone induced the formation of a small number of mineralized nodules scattered under the field of vision; however, there was no significant difference in comparison with the control group (Fig. 6B). In the $\mathrm{Mg}$ only group, the proportion of the stained area in the culture plate increased to a marginally higher level than that of the counterpart LIPUS only group (Fig. 6B). The combination of LIPUS and $\mathrm{Mg}$ treatment resulted in prominent and maximum mineralized nodule formation, which exhibited cloud-shaped morphology, demonstrating that co-stimulation had a synergistic effect on increasing extracellular matrix calcium accumulation and anabolic activity during bone cell metabolism (Fig. 6B).

Expression profiles of representative DEGs associated with migration in the $M g$ and LIPUS combination group. The expression of tumor necrosis factor- $\alpha$ (TNF- $\alpha$ ), c-Jun N-terminal kinase (JNK), p38 MAPK (P38), MAPK-activated protein kinase (MAPKAPK)2, MAPKAPK3, doublecortin (DCX), paxillin (PXN) and Jun proto-oncogene AP-1 transcription factor subunit (JUN) was determined by microarray, 


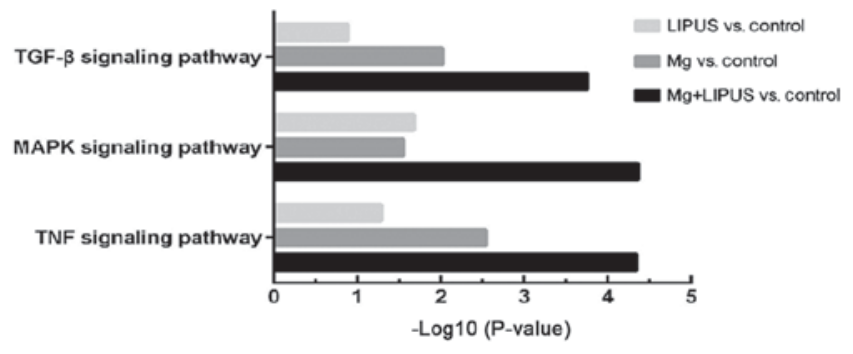

Figure 3. KEGG analysis of the identified DEGs. The KEGG database was used to further characterize the metabolic pathways of the DEGs identified in the treatment groups. The enrichment scores of the TGF- $\beta$, MAPK and TNF signaling pathways were ranked by-log10 (P-value). KEGG, Kyoto Encyclopedia of Genes and Genomes; DEGs, differentially expressed genes; TGF- $\beta$, transforming growth factor- $\beta$; MAPK, mitogen-activated protein kinase; TNF, tumor necrosis factor; LIPUS, low-intensity pulsed ultrasound; $\mathrm{Mg}$, magnesium.

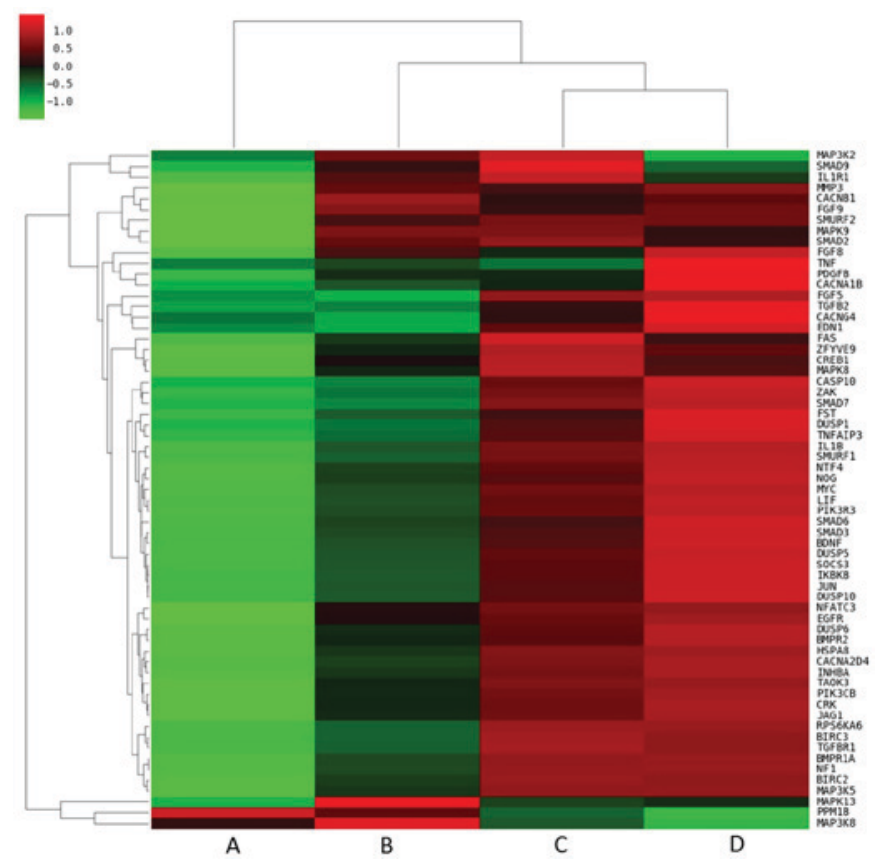

Figure 4. Cluster analysis of the 64 identified differentially expressed genes in the transforming growth factor- $\beta$, mitogen-activated protein kinase and tumor necrosis factor signaling pathways. A indicates the control group, B indicates the LIPUS alone group, $\mathrm{C}$ indicates the $\mathrm{Mg}$ alone group and $\mathrm{D}$ indicates the combined $\mathrm{Mg}+$ LIPUS treatment group. Each column represents an experimental condition relative to group A and each row represents a gene. Red and green indicate upregulation and downregulation, respectively. LIPUS, low-intensity pulsed ultrasound; $\mathrm{Mg}$, magnesium.

as these genes are strongly associated with cell migration. Compared with the control group, JNK, p38, MAPKAPK2, MAPKAPK3, DCX, PXN and JUN were all downregulated in the LIPUS only group. In the Mg alone group, JNK and JUN were upregulated, while the expression of PXN was decreased, compared with the control group. In the combination group, the expression of JNK, P38, DCX, PXN and JUN was significantly increased compared with control, while the expression of TNF- $\alpha$, JNK, P38 and JUN was significantly increased compared with Mg only and LIPUS only groups, indicating that the combination of $\mathrm{Mg}$ and LIPUS treatment had a synergistic effect on migration (Fig. 7).

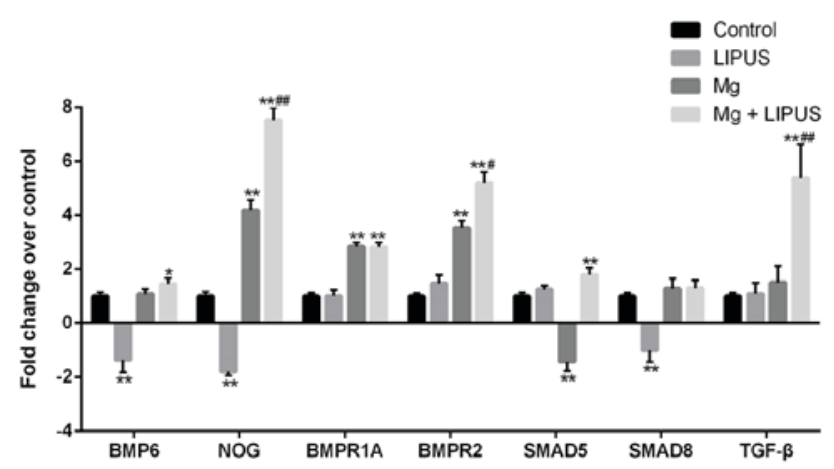

Figure 5. Expression profiles of representative differentially expressed gene associated with bone mineralization in osteoblasts treated with $\mathrm{Mg}$ only, LIPUS only or with combinative treatment, as determined by microarray analysis. Data are presented as a fold-change relative to an arbitrary value of 1 for control cells. ${ }^{*} \mathrm{P}<0.05$ and ${ }^{* *} \mathrm{P}<0.01$ vs. control group; ${ }^{*} \mathrm{P}<0.05$ and ${ }^{\# \#} \mathrm{P}<0.01$ vs. Mg alone and LIPUS alone groups $\mathrm{n}=3$. Mg, magnesium; LIPUS, low-intensity pulsed ultrasound; BMP, bone morphogenetic protein; NOG, noggin; BMPR, bone morphogenetic protein receptor.

These data were also consistent with the results of a wound healing assay, which was used to capture representative images of migrated osteoblasts in response to an artificially induced scratch-wound. Initially, the current study determined whether LIPUS, as an established inducing stimulus for mechanosensitive cells, may accelerate osteoblast migration. However, the results of the present study indicated that compared with the control group, the wound healing ability of osteoblasts was not significantly altered following LIPUS treatment alone after $24 \mathrm{~h}$ (Fig. 8). It was also determined whether $\mathrm{Mg}$, an essential element in various biological processes, was involved in osteoblast migration. In the $\mathrm{Mg}$ alone group, the total number of cells that had migrated into the scratch area was significantly increased compared with the control group, indicating that the $\mathrm{Mg}$ ions promoted osteoblast migration to repair the wound area (Fig. 8). Furthermore, it was observed that the number of migrated cells was significantly promoted compared with the single treatments in the combinative treatment group, indicating that combined Mg and LIPUS treatment had a tendency to accelerate the speed of wound repair by promoting cell migration (Fig. 8).

Expression pattern of metal transporter genes associated with $\mathrm{Mg}$ entry following $\mathrm{Mg}$ and LIPUS combinative treatment. To elucidate alterations in metal transporter gene expression associated with Mg entry in to hFOB1.19 osteoblasts, the expression of six candidate metal transport genes was examined across the four groups by microarray analysis: Cyclin and CBS domain divalent metal cation transport mediator 2(CNNM2), $\mathrm{K}^{+}$voltage-gated channel subfamily $\mathrm{J}$ member 14 (KCNJ14), TRP subfamily M member 7 (TRPM7), TRPV2, ATPase $\mathrm{Na}^{+} / \mathrm{K}^{+}$transporting subunit $\alpha 1$ (ATP1A1) and $\mathrm{KCNJ} 2$, as described in our previous study (29). Initially, the three treatments groups were compared with the control group. In the LIPUS alone group, CNNM2, KCNJ14 and TRPM7 were upregulated, while ATP1A1 was downregulated, compared with the control group. In the $\mathrm{Mg}$ alone group, ATP1A1 was downregulated, while the other metal transporter genes did not exhibit significantly altered expression. In the combination group, ATP1A1, CNNM2, KCNJ14, 
A

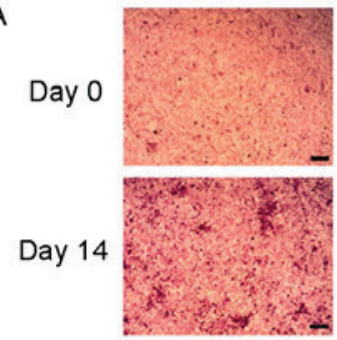

Control

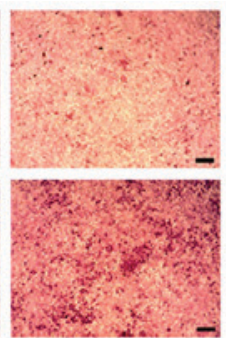

LIPUS

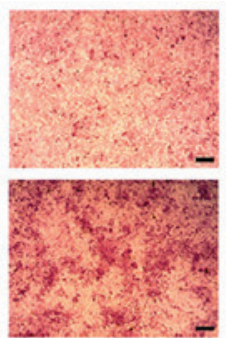

$\mathrm{Mg}$

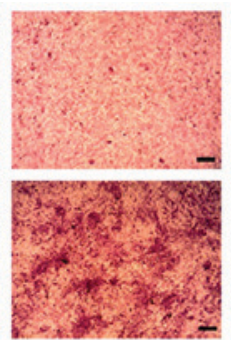

Mg+LIPUS
B

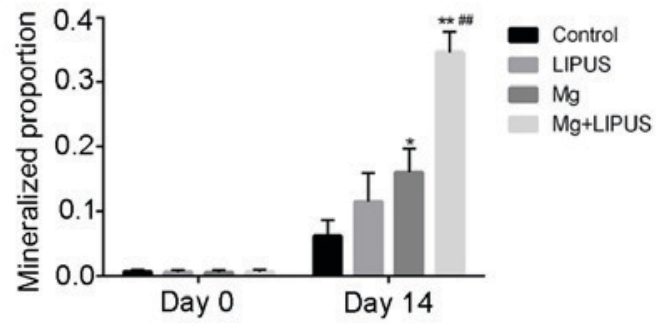

Figure 6. Alizarin Red S staining for calcium accumulation in hFOB1.19 osteoblasts following treatment with Mg alone, LIPUS alone or combinative treatment. (A) Cells in each group were individually cultured in 6-well plates for 0 and 14 days. Extracellular matrix calcium deposits representing matrix mineralization were detected with alizarin red S. (B) Quantification of alizarin red S staining demonstrated that LIPUS and Mg combination treatment accelerated bone nodule formation in hFOB1.19 osteoblasts, compared with the control, LIPUS alone and Mg alone groups. $\mathrm{n}=6$. Magnification, $\mathrm{x} 100$. Scale bar, $100 \mu \mathrm{m} .{ }^{*} \mathrm{P}<0.05$ and ${ }^{* *} \mathrm{P}<0.01$ vs. control group; ${ }^{\# \#} \mathrm{P}<0.01$ vs. Mg alone and LIPUS alone groups. Mg, magnesium; LIPUS, low intensity pulsed ultrasound.

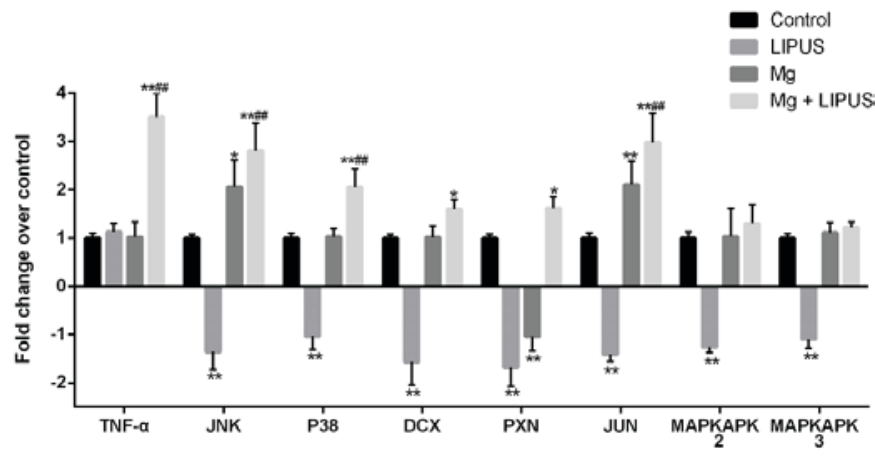

Figure 7. Expression profiles of representative differentially expressed genes associated with migration in osteoblasts treated with Mg only, LIPUS only or with combinative treatment, as determined by microarray analysis. Data are presented as a fold-change relative to an arbitrary value of 1 for control cells. ${ }^{*} \mathrm{P}<0.05$ and ${ }^{* *} \mathrm{P}<0.01$ vs. control group; ${ }^{\# \#} \mathrm{P}<0.01$ vs. $\mathrm{Mg}$ alone and LIPUS alone groups. $\mathrm{n}=3$. Mg, magnesium; LIPUS, low-intensity pulsed ultrasound; JNK, c-Jun N-terminal kinase; MAPK, mitogen-activated protein kinase; P38, p38 MAPK; MAPKAPK, MAPK-activated protein kinase; DCX, doublecortin; PXN, paxillin; JUN, Jun proto-oncogene AP-1 transcription factor subunit.

TRPM7 and TRPV2 were upregulated, whereas KCNJ2 expression was not altered, compared with the control group (Fig. 9). In comparison with the Mg alone group, CNNM2 and TRPM7 were upregulated in the LIPUS alone group, whereas in the combination group, ATP1A1, CNNM2, KCNJ14, TRPM7 and TRPV2 were upregulated compared with the Mg alone group, indicating that $\mathrm{Mg}$ ion alone treatment may not have induced the expression of $\mathrm{Mg}$ entry transporter genes, whereas LIPUS may have facilitated increased Mg entry by inducing $\mathrm{Mg}$ ion channel influx (Fig. 9).

$R T-q P C R$ validation of the expression levels of upregulated genes in hFOB1.19 osteoblasts. RT-qPCR was conducted to validate the expression levels of upregulated genes in the control, Mg only, LIPUS only and combinative treatment groups. Six candidate DEGs were selected for validation: BMPR2, JNK, P38, TGF- $\beta$, TNF- $\alpha$ and TRPM7. Overall, consistent with the microarray results presented in Figs. 5 and 9, the expression alterations of the DEGs exhibited similar trends and reached significance (Fig. 7). Notably, cells treated with the combination of $\mathrm{Mg}$ and LIPUS were markedly responsive through the TGF- $\beta$, MAPK and TNF signaling pathways, as evidenced by significant increases in BMPR2, JNK, P38, TGF- $\beta$ and TNF- $\alpha$ expression compared with control, $\mathrm{Mg}$ only and LIPUS only groups (Fig. 10). As presented in Fig. 8, JNK and P38 are expressed in the MAPK pathway, JNK, P38 and TNF- $\alpha$ are expressed in the TNF pathway, BMPR 2 and TGF- $\beta$ are expressed in the TGF- $\beta$ pathway. Furthermore, the expression levels of TRPM7 in the LIPUS only and combinative treatment groups were significantly upregulated compared with the control group; however, no significant difference in expression was observed in the $\mathrm{Mg}$ alone group (Fig. 10). Therefore, the microarray results may be reliable for quantitatively estimating the transcription levels of the tested transcripts.

\section{Discussion}

The primary function of osteoblasts is to proliferate and migrate towards the site of active bone formation, subsequently transforming into osteocytes that embed in the mineralized bone matrix. Therefore, identifying strategies to promote the osteogenic activity of osteoblasts during bony trabeculae formation has been an important focus of scientific investigation (33). As the eighth most abundant element in the Earth's crust by mass, Mg possesses similar mechanical properties to natural bone. Thus, Mg alloys or Mg-coated surfaces of metallic substrates have recently achieved great progress in orthopedic applications (2). Nevertheless, the optimal range of $\mathrm{Mg}$ concentration to induce bone formation requires evaluation to improve biosafety and biocompatibility at the cellular level. Hallab et al (34) reported that MG-63 cell proliferation decreased by $50 \%$ as $\mathrm{Mg}$ concentration increased to $7 \mathrm{mM}$, whereas the proliferation typically remained stable at low $\mathrm{Mg}$ concentrations. However, limited observation points were set in the range from 1.0 to $5.0 \mathrm{mM}$. Similarly, Wang et al (35) demonstrated $35 \mathrm{mM}$ as a critical concentration in terms of osteoblast safety, but gave few details regarding observations that cell proliferation exceeded $100 \%$ when $\mathrm{Mg}$ concentration reached 2-3 $\mathrm{mM}$, which may indicate that $\mathrm{Mg}$ ions enhance osteoblast proliferation. The aforementioned studies predominantly investigated the toxicity of high $\mathrm{Mg}$ concentration on osteoblasts, rather than the promotional effect of relatively low $\mathrm{Mg}$ concentrations. He et al (36) concluded that $3 \mathrm{mM} \mathrm{Mg}$ promoted cell proliferation, alkaline phosphate activity and osteocalcin levels in hFOB1.19 osteoblasts. However, it is difficult to eliminate other environmental factors, including anion 
A

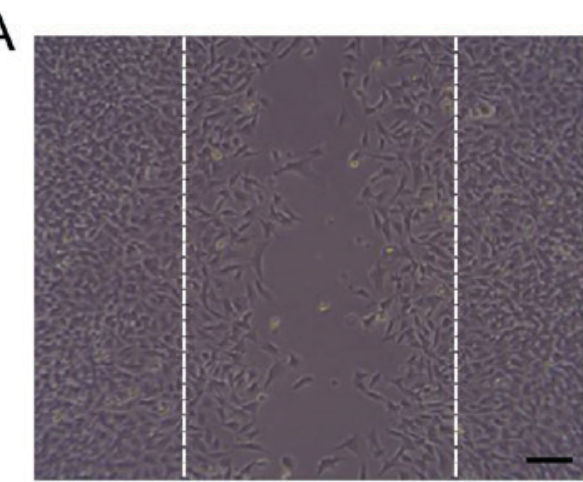

C

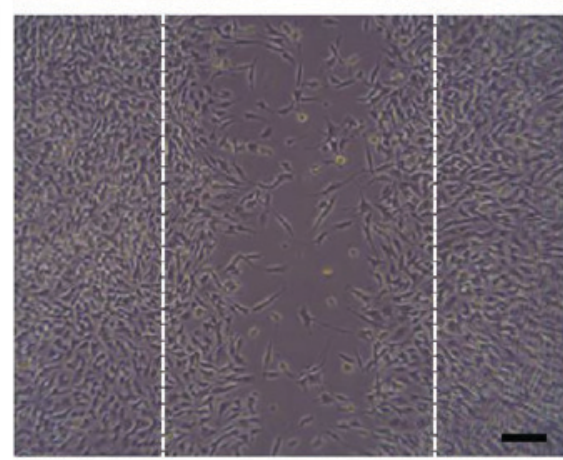

B

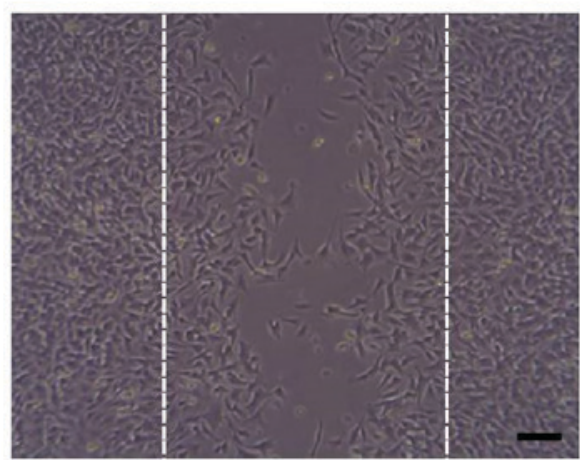

$\mathrm{D}$

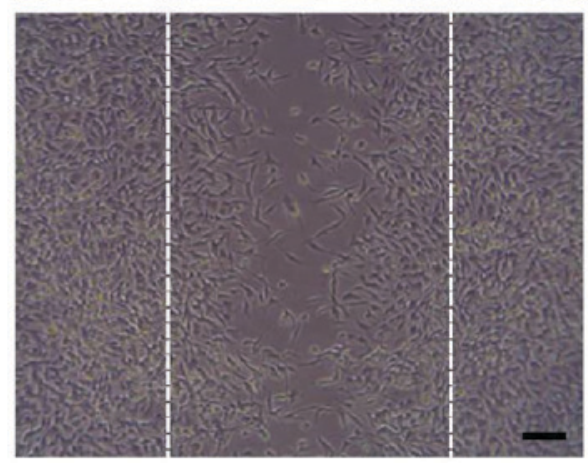

$\mathrm{E}$

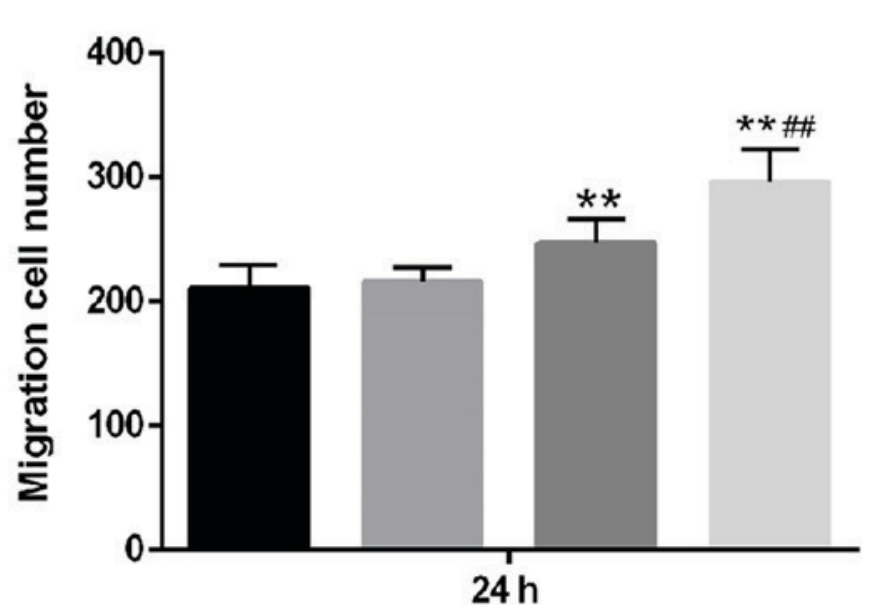

Control

LIPUS

$\mathrm{Mg}$

$\mathrm{Mg}+$ LIPUS capture representative images of migrated osteoblasts at $24 \mathrm{~h}$ in response to an artificially induced scratchwound in the (A) control, (B) LIPUS alone, (C) Mg alone and (D) Mg + LIPUS combination groups. (E) Quantification of the number of migrated cells demonstrated that the Mg and LIPUS combination group exhibited an accelerated speed of wound repair through increased cell migration after $24 \mathrm{~h}$, compared with the control, LIPUS alone and Mg alone groups. $\mathrm{n}=6$. Magnification, $\mathrm{x} 100$. Scale bar, $100 \mu \mathrm{m}$. ${ }^{* *} \mathrm{P}<0.01$ vs. control group; ${ }^{\# \#} \mathrm{P}<0.01 \mathrm{vs.} \mathrm{Mg}$ alone and LIPUS alone groups. Mg, magnesium; LIPUS, low-intensity pulsed ultrasound.

osmolality and $\mathrm{pH}$ alterations, which complicates the accurate determination of the optimum range of $\mathrm{Mg}$ concentration. In the present study, it was determined that the critical effective dose of $\mathrm{Mg}$ was $5 \mathrm{mM}$ and with combined exposure to LIPUS, the concentration with maximum effect reduced to $3 \mathrm{mM}$, which is an acceptable dose in terms of human tolerance without health risk concerns (13). Notably, this concentration induced osteogenesis with combined exposure to LIPUS in the present study.

LIPUS has been applied to accelerate bone fracture healing in clinical practice for over two decades. Previous studies have confirmed that LIPUS influences all major processes involved in osteogenesis, including osteoblast proliferation and differentiation, and mineralized nodule formation $(37,38)$. Furthermore, LIPUS and bioactive scaffold integration may overcome the limitations of bone grafting and other available surgical reconstructive techniques by delivering osteopregenitor cells to bone defects, thus providing novel medical applications for bone regeneration $(29,30)$. Therefore, the combinative effect of LIPUS and $\mathrm{Mg}$ on osteoinduction was investigated in the present study. In the CCK-8 assay, it was observed that the combination of LIPUS and Mg treatment increased osteoblast proliferation. To determine whether LIPUS and Mg exhibited a synergistic effect on mineralization, calcified nodule formation was examined by alizarin red $\mathrm{S}$ staining. The results indicated 


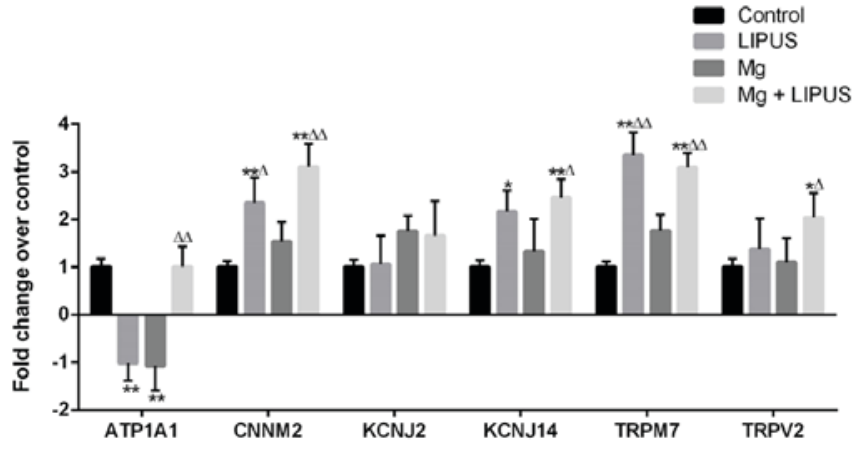

Figure 9. Expression pattern of metal transporter genes associated with $\mathrm{Mg}$ entry in osteoblasts treated with Mg only, LIPUS only or with combinative treatment, as determined by microarray analysis. Data are presented as a fold-change relative to an arbitrary value of 1 for control cells. ${ }^{\Delta} \mathrm{P}<0.05$ and ${ }^{\Delta \Delta} \mathrm{P}<0.01$ vs. Mg only group; ${ }^{*} \mathrm{P}<0.05$ and ${ }^{* *} \mathrm{P}<0.01$ vs. control group. $\mathrm{n}=3$. $\mathrm{Mg}$, magnesium; LIPUS, low-intensity pulsed ultrasound; ATP1A1, ATPase $\mathrm{Na}^{+} / \mathrm{K}^{+}$transporting subunit $\alpha 1$; CNNM2, cyclin and CBS domain divalent metal cation transport mediator $2 ; \mathrm{KCNJ}, \mathrm{K}+$ voltage-gated channel subfamily J; TRP, transient receptor potential cation channel.

that combinative treatment increased extracellular matrix calcium accumulation and anabolic activity during bone cell metabolism. A previous study by Man et al (39) revealed that pulsed $\mathrm{MHz}$ ultrasound may stimulate in vitro scratch wound healing through increased cell proliferation as well as migration. The migration assay in the present study indicated that LIPUS alone had no effect on osteoblast migration, whereas the combination of LIPUS and Mg significantly increased osteoblast migration compared with either LIPUS or $\mathrm{Mg}$ treatment alone.

In the current study, gene chip technology was used to analyze the molecular alterations in the different experimental groups, and the results revealed that combined $\mathrm{Mg}$ and LIPUS treatment significantly affected gene expression, as well as cytological properties, including 'SMAD protein phosphorylation', 'DNA duplication', 'metal ion binding', 'actin cytoskeleton function' and 'wound healing' GO terms, which were significantly upregulated. Notably, this synergistic stimulation predominantly occurred through the TGF- $\beta$, MAPK and TNF signaling pathways, which also facilitated $\mathrm{Mg}$ influx. This is schematically presented in Fig. 11, which depicts the proposed network of the combinative treatment influence on osteoblast proliferation, migration and mineralization.

The TGF- $\beta$ /BMP superfamily are widely involved in the regulation of bone organogenesis via receptor or kinase activation (40). In SMAD-dependent BMP signaling, TGF- $\beta$ binds to TGF- $\beta$ receptor type I and II, which results in signal transduction to the corresponding SMAD. NOG regulates BMP receptor association and SMAD1/5/8 signaling. Activated SMADs regulate the expression of transcriptional factors and coactivators in osteoblast differentiation and mineralization (31). In the present study, TGF- $\beta$ pathway proteins, including BMP6, NOG, BMPR1A, BMPR2, SMAD5 and SMAD8 were significantly upregulated in the combinative treatment group. Alterations in the expression of the key genes BMPR 2 and TGF- $\beta$ were also confirmed by RT-qPCR. Thus, it was concluded that the osteogenic effect of LIPUS and $\mathrm{Mg}$ in hFOB1.19 osteoblasts may be highly associated with TGF- $\beta$ signaling.

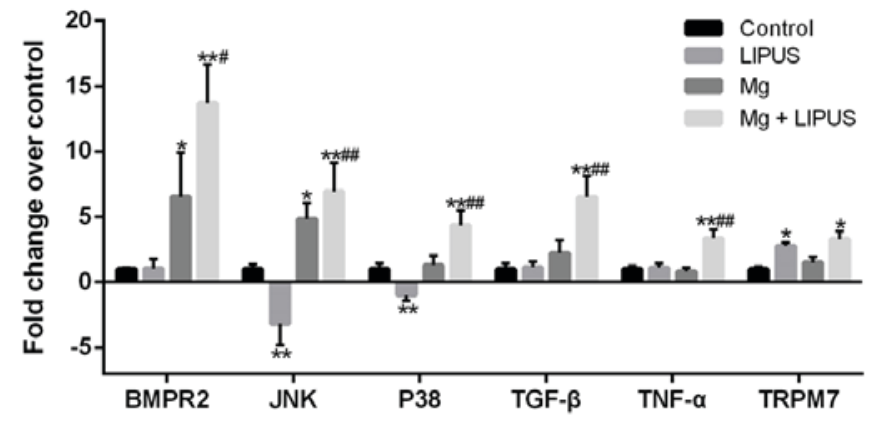

Figure 10. RT-qPCR validation of the microarray analysis. The RT-qPCR results were consistent with those of the microarray analysis, in that the six selected genes were differentially expressed with a similar trend. $\mathrm{n}=3$. ${ }^{*} \mathrm{P}<0.05$ and ${ }^{* *} \mathrm{P}<0.01$ vs. control group; ${ }^{\#} \mathrm{P}<0.05$ and ${ }^{\# \#} \mathrm{P}<0.01$ vs. $\mathrm{Mg}$ alone and LIPUS alone groups. RT-qPCR, reverse transcription-quantitative polymerase chain reaction; $\mathrm{Mg}$, magnesium; LIPUS, low-intensity pulsed ultrasound; BMPR2, bone morphogenetic protein receptor 2; JNK, c-Jun N-terminal kinase; P38, p38 mitogen-activated protein kinase; TGF- $\beta$, transforming growth factor- $\beta$; TNF- $\alpha$, tumor necrosis factor- $\alpha$; TRPM7, transient receptor potential cation channel subfamily M member 7 .

MAPKs, including JNK and P38, have an important role in cell migration (41). JNK regulates cell migration by phosphorylating its substrates, which include JUN, DCX and PXN (42-44). Furthermore, P38 has a regulatory role in migration by phosphorylating MAPKAPK 2 and MAPKAPK3, which may be essential for the directionality of migration $(45,46)$. It has previously been demonstrated that P38 activation may be associated with cytoskeletal reorganization and stimulation of cell motility in skeletal cells (47). A previous study reported that the inhibition of P38 prevented platelet-derived growth factor-induced migration of MC3T3 osteoblasts (48). The present study demonstrated the upregulation of P38 and JNK in the combined stimulation group, as well as a significant increase in the expression of downstream JUN components, DCX and PXN. The effect on JNK and P38 expression was confirmed by RT-qPCR. Taken together, these data indicated that combined LIPUS and Mg treatment induced JNK and P38 expression. Further gain and/or loss of function studies are required to confirm the role of the MAPK signaling pathway in combined $\mathrm{Mg}$ and LIPUS-induced osteoblast migration.

TNF- $\alpha$ is established as an inhibitor of osteoblast differentiation and an activator of osteoclastogenesis (49). However, it has been discovered that TNF- $\alpha$ may also promote osteogenic differentiation. These seemingly paradoxical effects were described as concentration-dependent in both in vitro and in vivo models (50-52). For example, in a murine model, lower concentrations of TNF- $\alpha$ (optimum, $1 \mathrm{pg} / \mathrm{ml}$ ) in the muscle distal to a fracture may promote migration of bone marrow mesenchymal stem cells. Following cell migration to the fracture site, local addition of TNF- $\alpha$ to achieve concentrations of $\sim 1 \mathrm{ng} / \mathrm{ml}$ at the fracture site subsequently inhibited further cell migration and promoted local osteogenesis (50). Notably, Mountziaris et al (51) demonstrated that the lowest dose of TNF- $\alpha(0.1 \mathrm{ng} / \mathrm{ml})$ was only sufficient to attenuate the effects of dexamethasone, which halts MSC osteogenic differentiation, whereas higher doses (5 and $50 \mathrm{ng} / \mathrm{ml}$ ) were able to exert a TNF- $\alpha$-induced effect on the MSCs, leading to an increased depth of cell infiltration as well as calcium deposition in a biodegradable polymeric microfiber scaffold. 


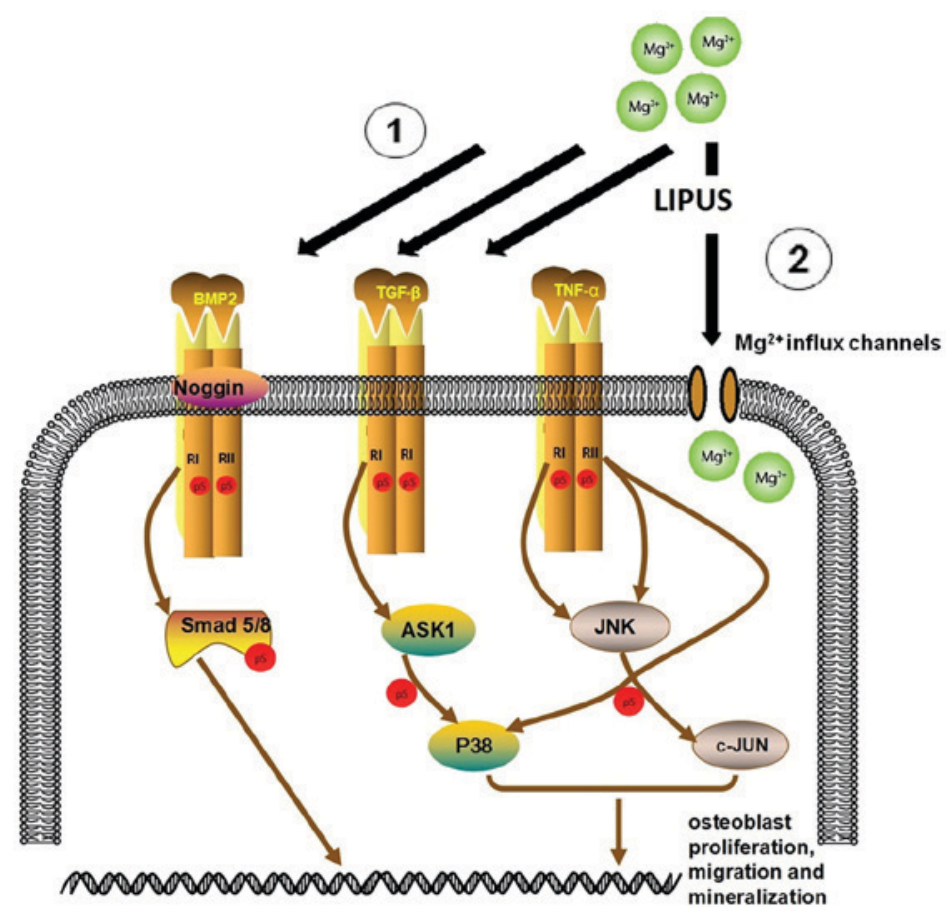

Figure 11. Schematic model of the effect of LIPUS and Mg combination treatment in hFOB1.19 osteoblasts. Arrow 1 depicts the involvement of the TGF- $\beta$, mitogen-activated protein kinase and TNF signaling pathways in the osteogenic effect of the combined stimulus. Arrow 2 indicates that combinative treatment may also facilitate Mg influx. Together these effects result in the increased proliferation, migration and mineralization activity of human osteoblasts. ASK1, apoptosis signal-regulating kinase 1; LIPUS, low-intensity pulsed ultrasound; Mg, magnesium; TGF- $\beta$, transforming growth factor- $\beta$; TNF- $\alpha$, tumor necrosis factor- $\alpha$; P38, p38 mitogen-activated protein kinase; JNK, c-Jun N-terminal kinase.

The promotion of osteogenic differentiation by TNF- $\alpha$ maybe via nuclear factor- $\kappa \mathrm{B}(\mathrm{NF}-\kappa \mathrm{B})$, which initiates BMP synthesis and matrix mineralization (52). Taken together, this indicates that in the combinative treatment, increased TNF- $\alpha$ signaling may be crucial in increasing osteoblast mineralization.

A study by Kubanek et al (31) revealed that ultrasound may stretch or displace the cellular membrane to alter the state of mechanosensitive ion channels embedded within the membrane, which would thus mediate transmembrane currents. This supported the findings of the present study, which demonstrated that combined treatment significantly upregulated metal transporter genes associated with Mg entry, including ATP1A1, CNNM2, KCNJ14, TRPM7 and TRPV2, when compared with $\mathrm{Mg}$ treatment alone. Additionally, metal ion binding was identified as an enriched process in the GO analysis of microarray results.

There are two potential explanations for the enhanced bone formation observed in the combination treatment group. The first is that the synergistic effect of Mg and LIPUS may have directly influenced the aforementioned upregulated pathways, resulting in increased proliferation, migration and mineralization activity in human osteoblasts. A further explanation for these effects may be that LIPUS mediated Mg ion influx, leading to TGF- $\beta$, MAPK and TNF signaling pathway upregulation. More advanced technologies, including fluorescent imaging, should be utilized for more precise measurement of in vitro data, in order to evaluate the association between $\mathrm{Mg}$ influx rate and osteogenesis, and to elucidate the specific mechanism of improved bone formation by combinative treatment with Mg and LIPUS.
In healthy individuals, $\mathrm{Mg}$ serum concentration is closely maintained within a physiological range. The normal reference range for serum $\mathrm{Mg}$ concentration is $0.76-1.15 \mathrm{mM}$; levels above this range is diagnosed as hypermagnesemia (53), the symptoms of which include hyporeflexia, hypotension, respiratory depression and cardiac arrest. Saris et al (13) previously reported that $3.5 \mathrm{mM}$ of $\mathrm{Mg}$ in the plasma was the critical level for human tolerance without concerns of health risks. Therefore, controlling local $\mathrm{Mg}$ release and promoting the transport efficiency of $\mathrm{Mg}$ ions into bone tissue are critical for biosafety in the application of biodegradable orthopedic Mg implants. The current study, to the best of our knowledge, is the first to propose a novel application of combining Mg with LIPUS in order to simultaneously reduce $\mathrm{Mg}$ degradation rate and enhance osteogenesis or osteoinduction. At a relatively low $\mathrm{Mg}$ concentration of $3 \mathrm{mM}$, LIPUS may possibly accelerate Mg ion transport, improve local utilization and in turn promote regeneration in human osteoblasts in vivo; however, further investigation is required. These effects may sequester the release of $\mathrm{Mg}$ ions away from systemic circulation, thus relieving its excretory burden in the kidneys and maintaining $\mathrm{Mg}$ serum at a level sufficient for implant biosafety. Prospective randomized clinical trials are required to validate this theory.

In conclusion, in the present study, combined treatment consisting of $\mathrm{Mg}$ ions and LIPUS was demonstrated to produce a synergistic effect on human osteoblast bone formation through the TGF- $\beta$, MAPK and TNF signaling pathways, whilst simultaneously facilitating $\mathrm{Mg}$ influx. Therefore, the combinative Mg and LIPUS treatment may have potential as a novel regenerative application for improving osteoinduction, 
as well as the biocompatibility and biosafety of biodegradable Mg implants.

\section{Acknowledgements}

We thank Dr Ruiqin Ma of Shanghai Oebiotech Co., Ltd., (Shanghai, China) for assistance of data analysis. We thank Dr Xi Zhan of the Dalian Institute of Chemical Physics, Chinese Academy of Sciences (Dalian, China) for technical advice. Additionally, we thank Dr Benjie Wang, Dr Baoyi Liu, Dr Xiaowei Wei and Dr Xiuzhi Zhang of Dalian University (Dalian, China) for their suggestions to improve the manuscript.

\section{Funding}

The present study was supported by the National Natural Science Foundation of China (grant no. 81672139).

\section{Availability of data and materials}

The datasets used and/or analyzed during the current study are available from the corresponding author on reasonable request.

\section{Authors' contributions}

DZ conceived and designed the study. HZ analyzed and interpreted the data regarding microarray assay and RT-qPCR analysis. XY performed in vitro assays to detect osteoblast biological function. $\mathrm{HZ}$ and $\mathrm{XY}$ contributed equally in writing the manuscript. All authors read and approved the final manuscript.

\section{Ethics approval and consent to participate}

Not applicable.

\section{Consent for publication}

Not applicable.

\section{Competing interests}

The authors declare that they have no competing interests.

\section{References}

1. Payr E: Beitrage zur technik der blutgefass- und nervennaht nebst mittheilungen über die verwendung eines resorbirbaren metalles in der chirurgie. Arch Klin Chir 62: 67-93, 1900 (In German).

2. Zhao D, Witte F, Lu F, Wang J, Li J and Qin L: Current status on clinical applications of magnesium-based orthopaedic implants: A review from clinical translational perspective. Biomaterials 112: 287-302, 2017.

3. Zhao D, Huang S, Lu F, Wang B, Yang L, Qin L, Yang K, Li Y, $\mathrm{Li}$ W, Wang W, et al: Vascularized bone grafting fixed by biodegradable magnesium screw for treating osteonecrosis of the femoral head. Biomaterials 81: 84-92, 2016.

4. Swaminathan R: Magnesium metabolism and its disorders. Clin Biochem Rev 24: 47-66, 2003.

5. Pasternak K, Kocot J and Horecka A: Biochemistry of magnesium. J Elementol 15: 601-616, 2010.

6. Jahnen-Dechent W and Ketteler M: Magnesium basics. Clin Kidney J 5 (Suppl 1): i3-i14, 2012.
7. Abed E and Moreau R: Importance of melastatin-like transient receptor potential 7 and magnesium in the stimulation of osteoblast proliferation and migration by platelet-derived growth factor. Am J Physiol Cell Physiol 297: C360-C368, 2009.

8. Ding S, Zhang J, Tian Y, Huang B, Yuan Y and Liu C: Magnesium modification up-regulates the bioactivity of bone morphogenetic protein-2 upon calcium phosphate cement via enhanced BMP receptor recognition and Smad signaling pathway. Colloids Surf B Biointerfaces 145: 140-151, 2016.

9. Rude RK, Gruber HE, Wei LY and Frausto A: Immunolocalization of RANKL is increased and OPG decreased during dietary magnesium deficiency in the rat. Nutr Metab (Lond) 2: 24, 2005.

10. Wang J, Ma XY, Feng YF, Ma ZS, Ma TC, Zhang Y, Li X, Wang L and Lei W: Magnesium ions promote the biological behaviour of rat calvarial osteoblasts by activating the PI3K/Akt signalling pathway. Biol Trace Elem Res 179: 284-293, 2017.

11. Gray J and Luan B: Protective coatings on magnesium and its alloys-a critical review. J Alloys Compd 336: 88-113, 2002.

12. Yamamoto A, Watanabe A, Sugahara K, Tsubakino H and Fukumoto S: Improvement of corrosion resistance of magnesium alloys by vapor deposition. Scr Mater 44: 1039-1042, 2001.

13. Saris NE, Mervaala E, Karppanen H, Khawaja JA and Lewenstam A: Magnesium. An update on physiological, clinical and analytical aspects. Clin Chim Acta 294: 1-26, 2000.

14. Zberg B, Uggowitzer PJ and Löffler JF: MgZnCa glasses without clinically observable hydrogen evolution for biodegradable implants. Nat Mater 8: 887-891, 2009.

15. Wang B, Zhao L, Zhu W, Fang L and Ren F: Mussel-inspired nano-multilayered coating on magnesium alloys for enhanced corrosion resistance and antibacterial property. Colloids Surf B Biointerfaces 157: 432-439, 2017.

16. Jiang Y, Wang B, Jia Z, Lu X, Fang L, Wang K and Ren F: Polydopamine mediated assembly of hydroxyapatite nanoparticles and bone morphogenetic protein-2 on magnesium alloys for enhanced corrosion resistance and bone regeneration. J Biomed Mater Res A 105: 2750-2761, 2017.

17. Li Z, Shizhao S, Chen M, Fahlman BD, Debao Liu and Bi H: In vitro and in vivo corrosion, mechanical properties and biocompatibility evaluation of $\mathrm{MgF}_{2}$-coated $\mathrm{Mg}-\mathrm{Zn}-\mathrm{Zr}$ alloy as cancellous screws. Mater Sci Eng C Mater Biol Appl 75: 1268-1280, 2017

18. Padilla F, Puts R, Vico L, Guignandon A and Raum K: Stimulation of bone repair with ultrasound. Adv Exp Med Biol 880: 385-427, 2016.

19. Poolman RW, Agoritsas T, Siemieniuk RA,Harris IA, Schipper IB, Mollon B, Smith M, Albin A, Nador S, Sasges W, et al: Low intensity pulsed ultrasound (LIPUS) for bone healing: A clinical practice guideline. BMJ 356: j576, 2017.

20. Alvarenga EC, Rodrigues R, Caricati-Neto A, Silva-Filho FC, Paredes-Gamero EJ and Ferreira AT: Low-intensity pulsed ultrasound-dependent osteoblast proliferation occurs by via activation of the P2Y receptor: Role of the P2Y1 receptor. Bone 46: 355-362, 2010.

21. Miyasaka M, Nakata H, Hao J, Kim YK, Kasugai S and Kuroda S: Low-Intensity pulsed ultrasound stimulation enhances Heat-shock protein 90 and mineralized nodule formation in mouse calvaria-derived osteoblasts. Tissue Eng Part A 21: 2829-2839, 2015.

22. Saini V, Yadav S and McCormick S: Low-intensity pulsed ultrasound modulates shear stress induced PGHS-2 expression and PGE2 synthesis in MLO-Y4 osteocyte-like cells. Ann Biomed Eng 39: 378-393, 2011.

23. Wang FS, Kuo YR, Wang CJ, Yang KD, Chang PR, Huang YT, Huang HC, Sun YC, Yang YJ and Chen YJ: Nitric oxide mediates ultrasound-induced hypoxia-inducible factor-1alpha activation and vascular endothelial growth factor-A expression in human osteoblasts. Bone 35: 114-123, 2004

24. Yang Z, Ren L, Deng F, Wang Z and Song J: Low-intensity pulsed ultrasound induces osteogenic differentiation of human periodontal ligament cells through activation of bone morphogenetic protein-smad signaling. J Ultrasound Med 33: 865-873, 2014.

25. Kinami Y, Noda T and Ozaki T: Efficacy of low-intensity pulsed ultrasound treatment for surgically managed fresh diaphyseal fractures of the lower extremity: Multi-center retrospective cohort study. J Orthop Sci 18: 410-418, 2013.

26. Nolte P, Anderson R, Strauss E, Wang Z, Hu L, Xu Z and Steen RG: Heal rate of metatarsal fractures: A propensity-matching study of patients treated with low-intensity pulsed ultrasound (LIPUS) vs. surgical and other treatments. Injury 47: 2584-2590, 2016. 
27. Salem KH and Schmelz A: Low-intensity pulsed ultrasound shortens the treatment time in tibial distraction osteogenesis. Int Orthop 38: 1477-1482, 2014.

28. Seger EW, Jauregui JJ, Horton SA, Davalos G, Kuehn E and Stracher MA: Low-intensity pulsed ultrasound for nonoperative treatment of scaphoid nonunions: A meta-analysis. Hand (N Y): Apr 1, 2017 (Epub ahead of print).

29. Zhou X, Castro NJ, Zhu W, Cui H, Aliabouzar M, Sarkar K and Zhang LG: Improved human bone marrow mesenchymal stem cell osteogenesis in 3D bioprinted tissue scaffolds with low intensity pulsed ultrasound stimulation. Sci Rep 6: 32876, 2016.

30. Nagasaki R, Mukudai Y, Yoshizawa Y, Nagasaki M, Shiogama S, Suzuki M, Kondo S, Shintani S and Shirota T: A combination of low-intensity pulsed ultrasound and nanohydroxyapatite concordantly enhances osteogenesis of adipose-derived stem cells from buccal fat pad. Cell Med 7: 123-131, 2015.

31. Kubanek J, Shi J, Marsh J, Chen D, Deng C and Cui J: Ultrasound modulates ion channel currents. Sci Rep 6: 24170, 2016.

32. Livak KJ and Schmittgen TD: Analysis of relative gene expression data using real-time quantitative PCR and the 2(-Delta Delta C(T)) method. Methods 25: 402-408, 2001.

33. Franz-Odendaal TA, Hall BK and Witten PE: Buried alive: How osteoblasts become osteocytes. Dev Dyn 235: 176-190, 2006.

34. Hallab NJ, Vermes C, Messina C, Roebuck KA, Glant TT and Jacobs JJ: Concentration- and composition-dependent effects of metal ions on human MG-63 osteoblasts. J Biomed Mater Res 60: 420-433, 2002.

35. Wang J, Witte F, Xi T, Zheng Y, Yang K, Yang Y, Zhao D, Meng J, Li Y, Li W, et al: Recommendation for modifying current cytotoxicity testing standards for biodegradable magnesium-based materials. Acta Biomater 21: 237-249, 2015.

36. He LY, Zhang XM, Liu B, Tian Y and Ma WH: Effect of magnesium ion on human osteoblast activity. Braz J Med Biol Res 49: pii, 2016. doi: 10.1590/1414-431X20165257.

37. Suzuki A, Takayama T, Suzuki N, Sato M, Fukuda T and Ito K: Daily low-intensity pulsed ultrasound-mediated osteogenic differentiation in rat osteoblasts. Acta Biochim Biophys Sin (Shanghai) 41: 108-115, 2009.

38. Wu S, Kawahara Y, Manabe T, Ogawa K, Matsumoto M, Sasaki A and Yuge L: Low-intensity pulsed ultrasound accelerates osteoblast differentiation and promotes bone formation in an osteoporosis rat model. Pathobiology 76: 99-107, 2009.

39. Man J, Shelton RM, Cooper PR, Landini G and Scheven BA: Low intensity ultrasound stimulates osteoblast migration at different frequencies. J Bone Miner Metab 30: 602-607, 2012.

40. Rahman MS, Akhtar N, Jamil HM, Banik RS and Asaduzzaman SM: TGF- $\beta$ /BMP signaling and other molecular events: Regulation of osteoblastogenesis and bone formation. Bone Res 3: 15005, 2015

41. Huang C, Jacobson K and Schaller MD: MAP kinases and cell migration. J Cell Sci 117: 4619-4628, 2004.
42. Gdalyahu A, Ghosh I, Levy T, Sapir T, Sapoznik S, Fishler Y, Azoulai D and Reiner O: DCX, a new mediator of the JNK pathway. EMBO J 23: 823-832, 2004.

43. Huang C, Rajfur Z, Borchers C, Schaller MD and Jacobson K: JNK phosphorylates paxillin and regulates cell migration. Nature 424: 219-223, 2003.

44. Javelaud D, Laboureau J, Gabison E, Verrecchia F and Mauviel A: Disruption of basal JNK activity differentially affects key fibroblast functions important for wound healing. J Biol Chem 278: 24624-24628, 2003

45. Hannigan MO, Zhan L, Ai Y, Kotlyarov A, Gaestel M and Huang CK: Abnormal migration phenotype of mitogen-activated protein kinase-activated protein kinase 2-/- neutrophils in Zigmond chambers containing formyl-methionyl-leucyl-phenylalanine gradients. J Immunol 167: 3953-3961, 2001.

46. McLaughlin MM, Kumar S, McDonnell PC, Van Horn S, Lee JC, Livi GP and Young PR: Identification of mitogen-activated protein (MAP) kinase-activated protein kinase-3, a novel substrate of CSBP p38 MAP kinase. J Biol Chem 271: 8488-8492, 1996.

47. Rodriguez-Carballo E, Gámez B and Ventura F: p38 MAPK signaling in osteoblast differentiation. Front Cell Dev Biol 4: 40 2016.

48. Mehrotra M, Krane SM, Walters K and Pilbeam C: Differential regulation of platelet-derived growth factor stimulated migration and proliferation in osteoblastic cells. J Cell Biochem 93: 741-752, 2004.

49. Osta B, Benedetti G and Miossec P: Classical and paradoxical effects of TNF- $\alpha$ on bone homeostasis. Front Immunol 5: 48, 2014.

50. Glass GE, Chan JK, Freidin A, Feldmann M, Horwood NJ and Nanchahal J: TNF-alpha promotes fracture repair by augmenting the recruitment and differentiation of muscle-derived stromal cells. Proc Natl Acad Sci USA 108: 1585-1590, 2011.

51. Mountziaris PM, Dennis Lehman E, Mountziaris I, Sing DC, Kasper FK and Mikos AG: Effect of temporally patterned TNF- $\alpha$ delivery on in vitro osteogenic differentiation of mesenchymal stem cells cultured on biodegradablepolymer scaffolds. J Biomater Sci Polym Ed 24: 1794-1813, 2013.

52. Hess K, Ushmorov A, Fiedler J, Brenner RE and Wirth T: TNF-alpha promotes osteogenic differentiation of human mesenchymal stem cells by triggering the NF-kappaB signaling pathway. Bone 45: 367-376, 2009.

53. Gröber U, Schmidt J and Kisters K: Magnesium in prevention and therapy. Nutrients 7: 8199-8226, 2015.

This work is licensed under a Creative Commons Attribution-NonCommercial-NoDerivatives 4.0 International (CC BY-NC-ND 4.0) License. 